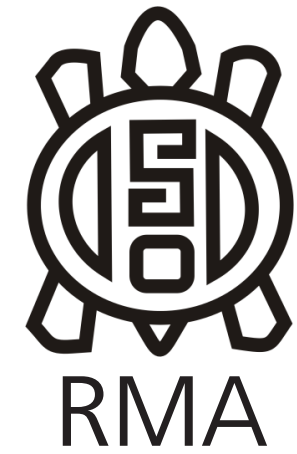

Museología

\title{
O Silenciamento do Negro no Museu Afro- brasileiro de Sergipe/Brasil
}

\author{
The Black Silencing at the Afro-Brazilian Museum of Sergipe / Brazil
}

Priscila Maria de Jesus*, Sura Souza Carmo** y Cristina Valença de Almeida Cunha Barroso**

\footnotetext{
* Universidade Federal de Sergipe. E-mail: priscilamdj@gmail.com ** Universidade Federal de Sergipe. E-mail: suracarmo@yahoo.com.br *** Universidade Federal de Sergipe. E-mail: tina_valenca@yahoo.com.br
}

\begin{abstract}
Resumo
A discussão sobre a ausência ou silenciamento de um protagonismo negro no estado de Sergipe parte-se do levantamento de fontes em jornais, livros e da composição do próprio acervo do primeiro museu do tema implantado no Brasil, o Museu Afro-brasileiro de Sergipe (MABS), no ano de 1976. O texto objetiva analisar o discurso expográfico do MABS, a partir da dicotomia senhor de engenho x escravização que é traçada ao longo da exposição de longa duração, que apresenta parte do projeto expográfico datado de sua abertura. Por metodologia optou-se pela pesquisa qualitativa, que buscou analisar as implicações dos documentos levantados, sobretudo as informações que são disponibilizadas para o público visitante do museu por meio dos seus textos expositivos. Conclui-se que é necessário pensar novas narrativas, para além da oficial, que tenham como fio condutor as reflexões, debates e considerações sobre aqueles que foram esquecidos pela história oficial.
\end{abstract}

Palavras-chave: Decolonial, Comunicação, Informação.

\begin{abstract}
The discussion about the absence or silencing of black protagonism in the state of Sergipe is based on the survey of sources in newspapers, books and the composition of the collection of the first museum on the subject implemented in Brazil, the Museu Afro-brasileiro de Sergipe (MABS), in 1976. The text aims to analyze the expographic discourse of MABS, from the dichotomy lord of plantation $x$ enslavement that is traced throughout the long-term exhibition, which presents part of the expographic project dating from its opening. Methodology opted for qualitative research, which sought to analyze the implications of the documents collected, especially the information that is made available to the museum's visiting public through its exhibition texts. It is concluded that it is necessary to think of new narratives, in addition to the official one, which have as a guiding thread the reflections, debates and considerations about those that were forgotten by official history.
\end{abstract}

Keywords: Decolonial, Communication, Information.

A compreensão das representações e ausências da cultura afrodiaspórica no Museu Afro-brasileiro de Sergipe perpassa o conhecimento da colonização do território sergipano, através das atividades econômicas desenvolvidas, os locais de maior concentração de escravizados e remanescentes de suas práticas culturais. As terras correspondentes a Sergipe d'El Rey eram habitadas por povos indígenas que tentaram resistir à colonização, sucumbindo em 1591, por aniquilamento via determinação real - e com recursos financeiros da Casa da Torre, da família D’Ávila, da Bahia (Antonio, 2012). Inicialmente a criação de gado foi a principal cultura, abastecendo as regiões de atividade canavieira da Bahia e Pernambuco, sendo a presença de escravizados da África noticiada desde a dominação dos colonizadores e fundação da cidade de São Cristóvão (Mott, 2008).

Os escravizados da província de Sergipe d'El Rey eram provenientes da Bahia e, de modo semelhante, possuíam a mesma predominância de grupos étnicos (Mott, 2008). Até o final do século XVIII, a primazia era de negros Bantos, sobretudo Angolas e, posteriormente, principalmente no início do século XIX, a Bahia e por decorrência Sergipe, recebeu levas de escravos sudaneses, denominados Jejes e 
Nagôs (Amaral, 2012). Impulsionado pela alta do mercado externo, no final do século XVIII Sergipe passou a produzir açúcar em grande quantidade, necessitando, por isso, de maior contingente de mão-de-obra escrava. De acordo com Mott (2008), devido à entrada de escravizados em Sergipe ser a partir de Salvador, houve uma menor quantidade de nativos africanos e maior número de afrodescendentes nascidos na colônia.

O território sergipano é cortado por rios de fácil navegação, que além do rio São Francisco possui os rios Piauí, Vaza-Barris, Cotinguiba e Japaratuba. A concentração de escravizados realizou-se nas culturas às margens dos rios. A lavoura canavieira rendeu tão bons lucros na primeira metade do século XIX que se expandiu para regiões dedicadas antes à criação de gado e lavoura de subsistência, espalhando por todo o território os negros escravizados. Sergipe chegou a possuir, em 1863, 830 engenhos, bem menores que os da Bahia e Pernambuco, mas que utilizava o trabalho escravo até o fim da escravidão (Almeida, 1984). Esse autor acredita que a região que concentrava o maior quantitativo de negros e maior produção de açúcar de Sergipe era o vale do Contiguiba, onde fica a cidade de Laranjeiras e o Museu Afrobrasileiro de Sergipe.

Diversos estudos historiográficos têm de debruçado sobre a escravidão no vale do Contiguiba, ressaltando as lutas pela liberdade, o cotidiano escravo (alimentação, religiosidade, residência, etc.) e o protagonismo negro (Resende, 2003; Amaral, 2012). As pesquisas têm revelado não apenas os aspectos cruéis da escravização, mas as diversas formas de resistência de sua cultura e identidade, principalmente através das manifestações culturais que hoje compõem grande parte do patrimônio imaterial sergipano, que descrevem um pouco da vida de escravizados, libertos e livres.

O conhecimento produzido sobre estes territórios e seu povo, na atualidade, principalmente no âmbito da História e da Antropologia, é uma importante ferramenta de decolonização dos museus. O olhar da decolonização contribui para refletir sobre concepções que antes tomavam como ponto de partida a construção epistemológica eurocêntrica, possibilitando um deslocamento do eixo de análise para produção científica e literária relacionadas à África e à América Latina.

Contudo, a decolonização do olhar nas políticas patrimoniais e na musealização de acervos é uma tarefa implementada principalmente pelos movimentos sociais, que vem ganhando visibilidade e ampliando sua margem de atuação nos espaços culturais e acadêmicos. De acordo com Matthias Assunção e Martha Abreu (2018):

A rediscussão dos africanismos no Brasil, ou da "extensão" das culturas africanas nas práticas culturais de setores negros e populares, tornou-se uma nova pauta de pesquisa de antropólogos, sociólogos e historiadores. Não mais sob a ótica das "expressões culturais" negras ou afro-brasileiras, mas sim a partir da ação de sujeitos sociais concretos que recriam os patrimônios herdados em diálogo com novos desafios e situações históricas concretas. (Assunção \& Abreu, 2018, p.25)

As políticas patrimoniais no Brasil durante muito tempo excluíram as manifestações relacionadas ao patrimônio afrodiaspórico em detrimento da valorização da herança luso-brasileira, sobretudo do período colonial, representado pelo tombamento de inúmeros edifícios históricos (Chuva, 2009). Durante mais de cinqüenta anos, o único bem tombado pelo IPHAN (Instituto do Patrimônio Histórico e Artístico Nacional), relacionada a herança de matriz africana, foram os objetos denominados pejorativamente de "Museu da Magia Negra", um conjunto de artefatos oriundos de apreensões da polícia no Rio de Janeiro, entre o final do século XIX e início do XX, sendo inscrito no Livro do Tombo Arqueológico, Etnográfico e Paisagístico e "primeiro tombamento de caráter etnográfico do país" (Guran, 2017, p.215).

O tombamento e a nomenclatura dada aos objetos patrimonializados pelo IPHAN caracterizam o modo como era ainda tratada a cultura afrobrasileira na década de 1930, em especial as religiões de matriz africana, em que objetos de culto eram apreendidos para estudo das características de seus usuários, desenvolvidos por profissionais que buscavam compreender, a partir da teoria de inferioridade racial, o comportamento dos negros e sua suposta peliculosidade. Apesar do tombamento, a valorização dos objetos como elementos da cultura afrodiaspórica não aconteceu na prática.

De acordo com Márcia Chuva (2017), apenas décadas depois, nas políticas do IPHAN, "o paradigma da excepcionalidade do patrimônio nacional" foi modificado marcando uma ação institucional que passou a perceber o bem como "peça do cotidiano, do mundo do trabalho, de religiosidades não dominantes, dos subalternos e das minorias e, nem por isso, menos significativo como referência de identidades e como fonte para a produção de conhecimento sobre a história do Brasil" (Chuva, 2017, p.82-83). Após conflitos e com a participação da comunidade, em 1984, o Terreiro da Casa Branca, foi tombado em Salvador, inaugurando um novo momento nas políticas patrimoniais brasileiras (Lima, 2012; Guran, 2017). Na atualidade, inúmeros terreiros já foram tombados, sobretudo na cidade de Salvador e na região do Recôncavo da Bahia, diminuindo a discrepância das tipologias de edificações tombadas pelo IPHAN, mas não em um todo.

A luta pela diminuição da ausência de representação do patrimônio afro-diaspórico nas políticas patrimoniais no 
Brasil foram reforçadas com a criação da Lei $n^{\circ} 3.551$ de 04 de agosto de 2000, que institui o registro do patrimônio imaterial, possibilitando a valorização de inúmeros bens em diversos pontos do território nacional. Apesar do número crescente de tombamento e registros de bens de origem africana, há ainda estereótipos e discursos que precisam ser revistos, nas políticas patrimoniais e nos discursos expográficos de instituições museológicas, a fim de reparar equívocos históricos e de representar, de forma efetiva, a contribuição africana na formação identitária do Brasil.

Desta forma, o presente artigo visa compreender as formas de construção de um discurso museográfico que passam pela compreensão e levantamento de seus objetos, recursos e textos utilizados. Ao se analisar o MABS optou-se por uma abordagem que priorizasse a pesquisa qualitativa, evidenciando uma análise interpretativa dos dados coletados a partir do diagnóstico da exposição do Museu Afro-brasileiro de Sergipe e das informações disponibilizadas para o visitante por meio das etiquetas dos objetos. Não obstante a importância das etiquetas como texto informativo, elas auxiliam na compreensão de como a narrativa expográfica está descrita.

A concepção deste objeto de estudo sugere a necessidade de direcionar um olhar para além da construção da narrativa expográfica, que suscita a compreensão histórica do espaço físico e toda a memória que estabelece possíveis conexões com a população da cidade de Laranjeiras. Ou seja, entendemos que é importante perceber o Museu Afro-brasileiro de Sergipe, associado ao movimento de luta social e política. Considerando a realidade atual do objeto de estudo, optou-se pela análise descritiva e revisão de literatura sobre o tema, por meio de periódicos como artigos, jornais e livros.

Para a classificação do acervo foi utilizado o Thesaurus para acervos museológicos (Ferrez \& Bianchini, 1987), obtidas a partir das etiquetas dos objetos em exposição. Ressalta-se que parte do acervo encontrase sem identificação, comprometendo o processo de comunicação da informação por parte do museu, e que o levantamento e tipificação em quadros foi realizado a partir do acervo arrolado, mas, por meio das tratativas e acordo entre as partes, prevê a não divulgação das imagens dos ambientes e objetos pesquisados. Segundo Eva Lamborghini (2019, p. 65) "Las etiquetas y los textos que acompañan a los objetos revelan, producen o -cuando menos- sugieren su significado". Questiona-se se a própria não etiquetação dos objetos existentes no museu consiste no início do processo de seu silenciamento, uma vez que apenas os objetos que estavam diretamente ligados à cultura africana careciam de informação. A significação dos objetos de cultura afrodiaspórica e sua representação nos espaços museais, demanda um esforço conjunto entre museu, funcionários e comunidade para que as informações apresentadas possam apresentar um panorama fidedigno da cultura negra e seus agentes, sem as camadas de silenciamento, folclorização e racismo.

O museu Afro-brasileiro de Sergipe nasceu a partir de uma proposta no Encontro Cultural de Laranjeiras em 1976. Destaca-se que a exposição de longa duração abarca os dois pisos do prédio, sendo que as salas localizadas no térreo - a sala do ciclo do açúcar, espaço do senhor de engenho e dos objetos de tortura. Embora as salas apresentem um tema que norteie a sua expografia, as mesmas não apresentam um título específico. As salas no pavimento térreo apresentam uma expografia datada de 1976, época da sua criação, incentivada por um grupo de intelectuais locais. Por outro lado, as salas que compõem o primeiro pavimento, apresentam uma maior rotatividade em sua expografia, o que dificulta precisar uma data específica. Nesse pavimento, destaca-se alguns aspectos culturais e religiosidade afro-brasileira.

\section{Narrativas, silenciamento e pensamento decolonial}

O processo de concepção de uma narrativa expositiva leva em conta a mensagem que a instituição pretende passar, que público pretende atingir e disponibilidade técnico/econômica da instituição. No que diz respeito à mensagem, está geralmente relacionada à missão da instituição, que norteia a seleção dos objetos que serão adquiridos e, posteriormente, farão parte da exposição de longa duração. Desta forma, a compreensão daquilo que o museu busca informar torna-se mais perceptível para o seu visitante. As exposições funcionam como o meio de comunicação e difusão do acervo de uma instituição, possibilitando, que o público tenha acesso a esta e aos resultados dos processos de conservação, pesquisa e documentação da instituição museológica. Segundo Fernández e Fernández (2017, p. 18) "La actividad expositiva resulta cada vez más atrayente y demandada por el público, como una de las funciones esenciales que deben cumplir los museos y centros especializados en beneficio de la comunidad a la que sirven o de la sociedad en general".

Nas últimas décadas percebe-se os avanços técnicos e o desenvolvimento de novas tecnologias para a comunicação e informação que podem ser utilizadas nos espaços museais para potencializar o desenho expográfico e processos de interpretação e apreensão por parte do público. As formas de se conceber uma exposição são variadas, no entanto, independente da técnica ou recurso utilizado o museu e seu corpo funcional tem por objetivo conceber formas de potencializar a comunicação da instituição com o seu público.

El diseño es un elemento esencial para el éxito de una exposición, y si en teoría existen muchos criterios y formas de diseñar una exposición, en la práctica los que condicionan los resultados 
positivos son la capacidad y la habilidad del diseñador para guiar y atraer la atención del público, y para que así pueda recibir mejor el mensaje. (Fernández \& Fernández, 2017, p. 19)

O Curador da exposição desenvolve o fio condutor da mensagem que será comunicada ao público ao percorrer o circuito expositivo, levando em consideração a missão e objetivos da instituição e aquilo a que ela se propõe para a comunidade. Mais do que apenas mostrar o objeto, contar sua história ou histórias por meio do seu acervo, o museu funciona como um espaço de informação e mediação do conhecimento. Ao se construir essa mensagem, ou narrativa expositiva, o profissional se atém a questões como objetividade, clareza da informação e pesquisa fundamentada, uma vez que ao se entrar no museu e se inserir em sua lógica museal, o que se apresenta passa a ser tida como "verdade" por quem o visita, uma vez que o museu é também um espaço de difusão do conhecimento.

Compreender os processos de formação das narrativas expositivas, permite compreender melhor a formação e vocação de um museu. Para Flórez Crespo "el museo es entendido como comunidad de aprendizaje, pero resultado de un proceso de negociación entre diferentes poderes (consórcios, comités de expertos, artistas, visitantes, comunidades, etc.) que son los que van a definir la política museal" (2006, p. 232). Neste processo de negociações e espaços multiculturais a museologia crítica, surge como esse entremeio de discussão e de voz para discursos que foram invisibilizados ao longo do tempo, através das trocas e negociações entre esses atores e a instituição museal que incorpora em seus processos de comunicação outras narrativas para além do discurso oficial e hegemônico.

Para Cury, "As contradições da transitoriedade do museu são inerentes ao entendimento de que o museu ainda se sustenta no ideal colonialista e hegemônico ao mesmo tempo quer descoloniar" (2019, p. 17), nessa perspectiva uma análise sobre a narrativa expositiva do Museu Afrobrasileiro de Sergipe (MABS) faz refletir sobre os tipos de narrativas que são construídas nos museus e o papel de uma museologia crítica no fazer museológico quando dá visibilidade para discursos diaspóricos.

O próprio processo de formação dos museus, ao serem analisados sob a perspectiva da decolonialidade carecem de um aporte teórico que o insira em um espaço de diálogos e embates sobre a formação cultural das sociedades que estão neles representadas. O desconhecimento e a falta de visibilidade de autores locais no desenvolvimento de teorias, sobretudo na Museologia, que tenham como centro os embates latinoamericanos, direciona as discussões a partir de autores europeus e suas realidades, em muito distante do vivenciado na
América Latina.

Autores como Cury (2019) e Brulon (2020) apresentam discussões sobre os processos de decolonização dos acervos e suas narrativas, no entanto, dentro dos próprios contextos nacionais, existem particularidades regionais e locais que precisam ser analisadas e entendidas pelos seus próprios pesquisadores, no que tange à cultura negra e seu silenciamento dentro das exposições, destaca-se o silenciamento dos autores negros refletindo sobre a questão.

A invisibilidade dos estudos sobre a Museologia, por um prisma que atenda as especificidades locais, as discussões decoloniais e que apresentem, sobretudo, autores não europeus, proporciona pouca literatura sobre o tema, seja de textos técnicos, construídos a partir, em grande parte, de museus que apresentam coleções majoritariamente de origem européia ou colonial branca.

Los procesos de etnicización y movilización cultural y política de grupos étnico-raciales al interior y a través de las fronteras nacionales han posibilitado, entre otras transformaciones, el cambio del museo de un sitio de memorias hegemónicas, a un espacio para la confrontación, negociación y empoderamiento de grupos subalternizados. (Lamborghini, 2019, p. 66)

Os museus afro-brasileiros, passam a ser construídos a partir da década de 1970 e 1980 com o fortalecimento do Movimento Negro no Brasil devido a busca pela preservação de sua identidade e representatividade no território nacional, para Lody (2005) essa demanda por representação a partir dos espaços museais é uma busca para a preservação não apenas de sua cultura material, mas, também das manifestações imateriais de origem africana, permitindo, assim, uma compreensão maior da simbologia e importância dessas culturas e favorecendo a diminuição de discursos de inferioridade das culturas afro-diaspóricas.

\section{Laranjeiras e o Museu Afro-brasileiro de Sergipe: breves incursões}

A cidade de Laranjeiras, no estado de Sergipe/Brasil, tornou-se conhecida por sua pluralidade cultural, reforçada pelas manifestações culturais que em grande parte derivam da matriz afro-brasileira, além de apresentar um rico e preservado patrimônio arquitetônico que remete ao período colonial. Laranjeiras tinha um lugar de destaque entre as cidades na produção da cana de açúcar no século XIX, por estar localizada na região da Cotinguiba, que era formada por engenhos, possuindo ainda um núcleo urbano dinâmico e politicamente influente. Essa prosperidade lhe proporcionou crescimento comercial, populacional e cultural visto através da monumentalidade 
dos sobrados, das igrejas, teatros, escolas, trapiche e da presença de um forte comércio. Oliveira Telles (2013) afirma que: "com o progresso da agricultura e do commercio ainda tornou-se Laranjeiras um centro litterário relativamente importante e bem digno de competir com sua rival a Estância" (Telles, 2013, p.81).

De acordo com Oliveira Telles (2013) em agosto de 1832, Laranjeiras foi elevada à categoria de villa e, em maio de 1848, tornou-se cidade. Nesse ínterim, Laranjeiras vivencia diversos conflitos sejam de ordem política, social, econômica ou mesmo religiosa. Entre os anos de 1835 e 1837, a cidade presenciou duas revoltas de escravizados e libertos, que marcaram a literatura como um dos importantes movimentos de luta negra em Sergipe pela liberdade. Já no final do século XIX, nos anos de 1870, ganhou destaque a perseguição a um dos maiores líderes negros de Sergipe, João Mulungu.

Laranjeiras também vivenciou conflitos políticos e ideológicos com a chegada do cientificismo e das ideias republicanas, registrada a efervescência dessas querelas nos jornais locais como por exemplo: "o Horizonte", "o Laranjeirense" e o "Republicano". Também foi palco de perseguições religiosas aos negros e aos protestantes, como relembra Nascimento (2004), o sincretismo religioso gerado pelo contato da cultura negra e a religião católica favoreceu a entrada de outros credos como o protestantismo, mas a custa de diversos embates:

Por possuir a maior população negra na época, em Laranjeiras suas representações religiosas sobreviveram às imposições do catolicismo, utilizando-se da linguagem católica, dos seus ritos e dos seus valores.(...) Mesmo consideradas pelos clérigos católicos e uma parte da elite como superstição e fanatismo as formas de expressão religiosas africanas proliferaram em Laranjeiras, propiciando uma diversidade religiosa e, por conseguinte, abrindo espaço para outros credos. (Nascimento, 2004, p. 112-113).

Por outro lado, a cidade de Laranjeiras constituiu em torno desses conflitos uma herança multicultural na qual estão presentes nas manifestações culturais, nos modos de pensar, ritos e festas, muitas dessas provenientes da cultura negra. Assim, a ideia de criação de instituições culturais para preservar o patrimônio veio a endossar a implantação do Museu Afro-brasileiro de Sergipe (MABS), em janeiro de 1976, por meio do decreto $n^{\circ} 3.339$.

Tal criação, decorrente de discussões que começam a ser feitas na segunda metade do século XX, motivam a criação do MABS logo após o Encontro Cultural de Laranjeiras de 1976, evento que reunia intelectuais envolvidos com a cultura local, que propuseram um projeto no qual a cultura de Laranjeiras fosse representada, incluindo assim as heranças afro brasileiras. Gomes, Santos e Ribeiro (2015) asseveram que o primeiro Encontro Cultural de Laranjeiras, em 1976, aconteceu nas dependências da Igreja Matriz e foi pensado como uma festa que reuniria as manifestações populares, o artesanato e a culinária, valorizando a cultura da comunidade. Foi a partir desse movimento cultural que o Museu Afro-brasileiro de Sergipe nasceu, afirmam esses autores.

De acordo com Reis "a missão institucional do MABS é narrar, através das atividades de pesquisa, preservação e comunicação, fragmentos da monocultura canavieira de Sergipe, enfatizando a participação do negro enquanto protagonista de todo o processo" (2016, p. 65). A partir da missão da instituição é possível perceber que: a) o museu enquanto um espaço de pesquisa, preservação e comunicação de seu acervo; b) o objeto de estudo das práticas mencionadas anteriormente estão voltadas para a monocultura canavieira em Sergipe, isso se torna interessante, pois esse tipo de economia se baseou na utilização da mão de obra escravizada e na afirmação de uma elite branca; c) por fim apresenta o papel do negro, mas não como um ser dissociado do processo escravista, com uma cultura e historicidade própria ou suas formas de resistência, mas o vincula ainda mais a noção do negro como uma "ferramenta" geradora de riquezas na economia açucareira.

Embora o MABS tenha sido o primeiro museu de vertente afro-brasileira instalado em solo nacional, percebe-se o que ele ainda é, no que Jeria, Stáffora, Cohen e Pegoraro, classificam de "Herederos de las tradiciones coloniales y de procesos de dominación y homogeneización interna" (2020, p. 140). Ou seja, as ideias ainda, nesse caso, de um Sergipe colonial estava tão latente no imaginário dos intelectuais que a construção do museu, que deveria ter como protagonista os negros e suas formas de resistência, subjugou este, atribuindo, mais uma vez, a noção de um ser passivo no processo de sua própria escravização.

O museu e o curador, ao conceber uma narrativa expositiva que silencia o negro, ao reforçar seu papel de escravizado, ou como no caso da missão do MABS, de força motriz para o desenvolviento de uma economia que foi responsável pela morte de milhões de negros ao longo de quase quatrocentos anos, se distacia de seu "papel social", como um espaço privilegiado para a construção do saber e difusão do conhecimento.

Desta forma, cada vez mais lançar olhares decolonizadores sobre espaços geradores da informação, a exemplo de museus, bibliotecas e arquivos, consiste em uma realidade iminente, uma que " La decolonialidad se piensa entonces desde una compleja red de relaciones étnicas, raciales, sexuales, epistémicas y de género, entre otras, que permanecen enraizadas en las sociedades colonizadas y que deben ser desconstruidas para redescubrir nuestra identidad regional política y cultural" (Gordillo Sánchez, 
2017, p. 136-137). Destaca-se, aqui alguns pontos que devem ser levados em consideração ao se pensar os museus com acervos afrodiaspóricos:

- Maior circulação de textos técnicos em Museologia de autores negros;

- Construção de pesquisas que tenham por finalidade a divulgação de materiais de coleções afro-diaspóricas;

- $\quad$ Revisão de processos curatoriais que apresentam a narrativa colonial, para apresentar uma vertente decolonial e de valorização de identidades e memórias regionais e locais;

- Narrativas transversais aos discursos oficiais que priorizem a cultura e memória das minorias.

Percorrer esse caminho é um processo lento, mas que precisa ser iniciado pelas instituições museais, para que cada vez mais se tornem espaços inclusivos e de identificação.

\section{MABS e a representação negra: um olhar para a museologia crítica}

Instalado em um casarão do século XIX, o Museu Afrobrasileiro de Sergipe, também conhecido popularmente como Museu Afrobrasileiro de Laranjeiras, sofreu adaptações para abrigar suas primeiras coleções. Dividido em dois pavimentos o MABS, apresentou ao longo de sua existência algumas mudanças em sua expografia, feitas pelas gestões que passaram pelo museu. A narrativa expositiva do museu, que apresenta 05 (cinco) salas de exposição de longa duração e 01 (uma) de exposição temporária, apresenta um claro embate no que diz respeito à mensagem que pretende passar, evidenciado pelo teor do seu acervo e sua disposição. A partir do levantamento do acervo em exposição e das informações que são disponibilizadas para os visitantes por meio de suas etiquetas e textos, percebe-se uma dicotomia na narrativa expográfica nas salas do térreo que consiste em Senhor de Engenho $x$ escravo.

Essa imagem do escravizado fica atrelada unicamente às suas formas de punição, sem abrir margem para discutir e apresentar as formas de resistências existentes, suas práticas sociais, como a própria formação do quilombo da Mussuca, localizado em Laranjeiras/SE, ou personalidades emblemáticas da cidade na luta pela liberdade e igualdade de direitos.
A exposição de longa duração está dividida em 05 salas em dois pavimentos, o térreo e o superior. No pavimento térreo temos as seguintes salas: 1) Sala dos equipamentos de engenho (composta por objetos utilizados na produção de açúcar); 2) Sala do senhorio (composta por móveis e uma cadeira de arruar colonial e a ambientação de uma cozinha senhorial); 3) instrumentos de tortura (composta por insrumentos que serviam para conter e/ou punir escravos fugidos). No pavimento superior temos: 1) salas dos orixás (composta por 12 manequins vestidos com indumentária de orixás doadas por terreiros da região); 2) sala do candomblé (com objetos de alguns candomblés de Laranjeiras).

A narrativa expositiva acaba por evidenciar os modos de vida e economia do branco no período do Brasil colonial, como demonstra o Quadro 01.

No Quadro 01 foram listados os objetos associados ao negro através do modo de vida do Senhor de engenho, sem uma relação profunda ao longo da exposição que garanta a sua presença dentro de um museu que fala sobre o afro-brasileiro, reforçando mais a história do branco colonizador, o que parte para o próprio questionamento de sua presença dentro desse museu, quando o Estado possui um Museu Histórico, na cidade de São Cristóvão. Enquanto força simbólica, esses objetos ficam dissociados de questionamentos como: quem é esse negro no estado de Sergipe? Quais suas formas de resistência? Como se deu seu processo migratório? Além, a narrativa existente reforça a sua presença "servil", ao dar espaço e protagonismo no museu ao branco que escravizou, não ao negro. O africano e seus descendentes não tem suas origens étnicas apresentadas ou qualquer descrição de aspectos culturais perpetuados durante a escravidão brasileira, ao contrário, reforça-se o discurso de coisificação, de mão-de-obra da casa-grande e do engenho.

Da mesma forma, o acervo exposto em longa duração, elencado no Quadro 02 mostra a divisão da visão do negro em duas vertentes: o escravizado castigado x sua relação com o candomblé, evidenciando os horrores da escravização sem abrir para que haja uma discussão crítica do processo e suas consequencias, para uma população de descendentes da escravização. A representação da religiosidade limita-se ao candomblé, sendo esta representante única no período do pós-abolição,

\begin{tabular}{|c|c|c|}
\hline N. de objetos & Classe & Tipo de exposição \\
\hline 02 & Acessório de transporte & Longa Duração \\
\hline 05 & Mobiliário & Longa Duração \\
\hline 02 & Transporte Terrestre & Longa Duração \\
\hline 06 & Equipamento Agricola & Longa Duração \\
\hline 03 & Objeto de iluminação & Longa Duração \\
\hline 18 & Utensílio de cozinha/mesa & Longa Duração \\
\hline 02 & Equipamento de serviço doméstico & Longa Duração \\
\hline
\end{tabular}

Quadro 01: Objetos da Casa grande e engenho Fonte: Arrolamento do acervo em exposição

Table 01 - Big House and Mill's objects Source: Listing of the collection on exhibition 


\begin{tabular}{|c|c|c|}
\hline N. de objetos & Classe & Tipo de exposição \\
\hline 10 & Instrumentos de castigo & Longa Duração \\
\hline 12 & Indumentária & Longa Duração \\
\hline 02 & Objeto de culto & Longa Duração \\
\hline 02 & Mobiliário & Longa Duração \\
\hline 05 & Documento & Longa Durãão \\
\hline 03 & Insígnia (atributo de divindade) & Longa Duraçã̃o \\
\hline 03 & Instrumento musical & Longa Duração \\
\hline 04 & Escultura & Longa Duração \\
\hline 08 & Documento & Temporária (não compõe o acervo permanente da instituição) \\
\hline
\end{tabular}

Quadro 02 - Relação de objetos relacionados ao afro-brasileiro sergipano

Fonte: Arrolamento do acervo em exposição

Table 02 - List of objects related to Afro-Brazilian Sergipe

Source: Listing of the collection on exhibition

negligenciando a presença da Umbanda, silenciando ainda os grupos de cultura popular de origem no período escravista e que perduram até os dias atuais, folguedos, ritos fúnebres, etc.

Ao se falar da presença do negro e das culturas afrodiaspóricas nos museus é necessário pensar suas formas de resistências, tensões e enfrentamentos, o que passa pela contextualização dos objetos bem como o lugar de fala desses indivíduos, que foram esquecidos ou silenciados nas narrativas dos museus, a exemplo do Museu Afro-brasileiro de Sergipe. Como ressalta Cunha (2006):

temos que incluí-los no universo de confrontos e intolerâncias culturais e suas dinâmicas; temos que pensar na construção e apresentação de patrimônios, memória e suas estratégias de lembrança e esquecimento, nas imagens construídas acerca da produção cultural e lugares sociais construídos e determinados (Cunha, 2006, p. 16).

Dentro dessa perspectiva, novas abordagens da cultura negra sergipana devem ser apresentadas na expografia de modo a desconstruir esse paralelo do negro/escravizado. Para além dos dados históricos referentes à escravidão, percebe-se que personalidades negras importantes para a memória de Laranjeiras foram silenciadas pelo MABS. São esses os líderes comunitários, professores, artistas, pessoas que apesar das adversidades representam a força e a importância do negro na formação do povo sergipano. No rol das possibilidades representativas que poderiam ser incluídas na expografia poderíamos citar João Mulungu, João Sapateiro e Zizinha Guimarães, todos personalidades negras provenientes da cidade de Laranjeiras.

\section{O MABS e as personalidades negras de Laranjeiras}

Para compreender um pouco da história de João Mulungu, líder negro de Laranjeiras, faz-se necessário perceber que as relações do regime escravista estavam eivadas de conflitos e contradições nem sempre esclarecidas pela literatura. Somado a esse fato, por se tratar de um momento histórico vivenciado ainda por volta do século XIX, as fontes disponíveis são escassas e, assim, as informações nem sempre estão acessíveis. Tem-se, portanto, indícios que marcam trajetos da sua história de vida.

Essa narrativa foi representada a partir da compreensão de que os escravizados, apesar da sua condição de expropriação civil, não eram passivos. João Mulungu foi um dos representantes e líderes da resistência negra em Sergipe, não só por ter fugido, mas por ser o líder de muitos negros fugidos no período, de acordo com Oliveira (2015) o Engenho Mulungu era de propriedade de João Pinheiro de Mendonça e ficava localizado no município de Laranjeiras, na região do Cotinguiba. A este engenho pertencia João Mulungu, que provavelmente foi adquirido ainda criança, diz Oliveira:

Porém, foi, sem sombra de dúvidas, o modo como vivenciou a sua experiencia de liberdade que abonou a identificacãa de João Mulungu como sendo o principal líder dos escravos fugidos de Sergipe Del Rey, ao longo da década de 1870, e, muitos anos depois, a sua elevação como o suposto representante das demandas sociais, sobretudo dos negros, em Sergipe nos anos de 1980 e 1990. (Oliveira, 2015, p.159)

Ao discutir sobre as interpretações construídas sobre os escravizados na literatura especializada, Oliveira (2015) refere-se a um gradual deslocamento na discussão sobre a escravização, ou seja, o escravizado passivo cede lugar ao guerreiro. Nessa direção, ilustra trabalhos como o de Severo D'acelino que retrata a figura de João Mulungu "como símbolo da resistência local", afirma: "Assim como Zumbi, Mulungu aparecia como um jovem enérgico, tenaz e que seria vencido apenas à custa de uma traição, optando, a partir de então, por ser enforcado em praça pública a sofrer novamente os suplícios do cativeiro" (Oliveira, 2015, p. 20).

De acordo com a pesquisa de Oliveira (2015) realizada 
nos autos de perguntas de 1871, informa que João Mulungu liderava cerca de 19 escravizados fugidos instalados em ranchos. Esses estavam localizados nas matas entre os engenhos Bom Sucesso, Limeira, São José e outros. Relata o autor que entre eles existiam redes de comunicações e trocas que colaboraram com a sobrevivência desses quilombos. Por diversas vezes as diligências ao partir em busca do grupo de escravizados não obtinham sucesso ficando João Mulungu cada vez mais conhecido, admirado por uns e temido por outros. Muitos crimes lhe foram impostos sem que realmente os tivesse realizado, acredita-se. Oliveira (2015) revela que sua prisão foi efetuada a partir da mudança de estratégia dos delegados de polícia que começaram a investigar tomando depoimentos das pessoas que mantinham contatos rotineiros com João Mulungu, como o Caso de Ana Rita, Vicência e Maria que eram protegidas e ganhavam com presentes, vestimentas e até quantias em dinheiro. Em 1873 foi preso e levado a julgamento. Hoje João Mulungu é um dos representantes da resistência negra da comunidade de Laranjeiras.

Outra personalidade um pouco menos controversa é João Sapateiro. Apesar de não ter nascido em Laranjeiras, ainda jovem se mudou para a cidade em busca de trabalho, assim como outros nesse período. João Silva Franco conquistou a alcunha de João Sapateiro ao adotar a profissão, diz Silva e Reis (2017). Sua história se protagoniza quando inicia uma segunda profissão, a de escritor/poeta. Mesmo não tendo instrução, seus textos revelam a simplicidade bem como sua expertise como cancioneiro das discrepâncias sociais e das condições de vida do povo de Laranjeiras, afirmam os autores. Atualmente a Prefeitura de Laranjeiras erigiu uma escultura em memória ao poeta e instituiu um prêmio literário em seu tributo. A construção do imaginário sobre essa figura que se tornou patrimônio de Laranjeiras demonstra o mérito de uma pessoa comum que se destacou na comunidade laranjeirense e atualmente representa a luta do movimento negro através da sua resistência.

E por fim, pode-se sugerir para compor a narrativa do Museu Afro-brasileiro de Sergipe a figura de Zizinha Guimarães. Isto não só por ser representativa da identidade negra, mas também por ter sido uma professora e artista respeitada entre a sociedade laranjeirense do final do século XIX e início do XX. De acordo com Freitas, VilasBoas e Nascimento (2002) Eufrozina Amélia Guimarães foi educada numa das escolas mais destacadas para o ensino feminino na época, o Colégio Inglês. Apesar de pertencer a uma família sem recursos e negra, ela recebeu uma das melhores instruções sendo aluna de Anne Carol, aponta Freitas, Vilas-Boas et al. (2002).

Destacou-se como aluna e posteriormente como professora, assim que formada passou a atuar no ensino dos jovens e comandava a Escola Laranjeirense, instituição respeitada e frequentada pelos filhos da elite laranjeirense do período, afirmam os autores. Segundo Santana (2011) a professora era requisitada pela sociedade para compor, participar e dirigir peças teatrais, eventos religiosos, assim como na apreciação das festas escolares. Os eventos, assim como os resultados finais da escola dirigida por Zizinha que eram publicadas nos jornais locais como grandes eventos. Diz Lívia Santana que: "A professora Zizinha era admirada por ser uma profissional dedicada, pelo seu compromisso com a vida social da cidade e pelos seus vários dotes artísticos" (2011, p. 10).

A maioria dos objetos pertencentes à Zizinha Guimarães encontram-se dispersos em Laranjeiras. Santana (2011) realizou um levantamento do acervo que representa parte da memória e da trajetória de vida de Zizinha, dentre eles aponta: o Órgão de Tubos localizado na Igreja Matriz; o Harmônio localizado no Museu de Arte Sacra; Livro escolar de História Natural que ela utilizava para ministrar suas aulas na Escola Laranjeirense; quadro de artistas que pintaram a professora, herma, diplomas e documentos de homenagens presentes no arquivo da Escola Estadual Zizinha Guimarães. Objetos que podem compor de forma harmônica juntamente com o acervo e uma nova proposta expográfica do Museu Afro-brasileiro de Sergipe.

\section{Considerações Finais}

O museu é um espaço polissêmico e polifônico em que diferentes discursos são elaborados com a finalidade de comunicar informações sobre uma dada realidade. Nos últimos anos, museus que possuem coleções relacionadas ao continente Africano e a diáspora africana têm revisto seus discursos, a fim de realizar reparações de equívocos históricos pautados em teorias raciais que foram superadas no âmbito acadêmico e precisam ser no âmbito social. Neste mesmo movimento, surgiram museus que tratam da questão da diáspora africana no Brasil, que ressaltam permanências e rupturas entre África e Brasil e como os afrodescendentes possuem uma história de lutas em prol de liberdade e igualdade de direitos e sociabilidades, a partir de coleções que demonstram um riquíssimo acervo material.

O Museu Afro-brasileiro de Sergipe nasce da vontade de mudar a história dos discursos expográficos que "coisificam" os indivíduos que foram escravizados no Brasil, pois surge em um contexto de lutas do movimento negro. Contudo, o discurso expográfico não condiz com as lutas contra o racismo nos anos de 1970, distanciando-se das pautas sociais e acadêmicas em voga. Há problemas no discurso, bem como na escolha do acervo, pois não representam o negro no território sergipano, no entanto rever essas questões tem-se mostrado cada vez mais difícil em uma instituição que ao invés de acompanhar e estimular as mudanças, tornase cada vez mais rígida e secular. É possível perceber 
que o MABS não foi criado para manter a memória dos senhores de engenho ou acadêmicos, mas sim de toda uma população que foi e é silenciada sistematicamente e que não tem representatividade no museu.

Percebe-se uma necessidade em rever o projeto expográfico, que apresenta um viés tradicional, analisando os temas e formas de expor, propondo uma crítica ao processo de escravização e o ser negro em Sergipe, através da ressignificação da exposição de longa duração de acordo com os princípios atuais abordados pela decolonização.

O caminho é lançar um olhar diferenciado para o passado e trazer elucidações sobre o tempo presente, onde ainda são latentes as cicatrizes deixadas pela escravização. É preciso um discurso em que o negro não seja apresentado como força motriz da sociedade escravocrata ou simplesmente silenciado, mas como agente basilar na construção da sergipanidade e da brasilidade.

\section{Referências}

Almeida, M. da G. (1984). Sergipe: fundamentos de uma economia dependente. Petropólis: Vozes.

Amaral, S. P. (2012). Um pé calçado, outro no chão: liberdade e escravidão em Sergipe (Contiguiba, 18601900). Salvador: EDUFBA; Aracaju: Editora Diário Oficial.

Antonio, E. M. M. (2012). A qualidade da terra e dos homens: colonização e posse de terras na América Portuguesa (Sergipe - século XVI-XVII). SAECULUM - REVISTA DE HISTÓRIA [26]; João Pessoa, jan./jun. 51-52. Disponível em: <http://periodicos.ufpb.br/ index.php/srh/article/viewFile/15032/8539>. Acesso: 20 abr. 2015.

Assunção, M., Abreu, Martha. (2018). Da Cultura Popular à Cultura Negra. Abreu, M. Xavier, G., Monteiro, L., Brasil, E. (Orgs.). Cultura negra: festas, carnavais e patrimônios negros. Vol. 1. Niterói: Eduff.

Brasil. Lei 3.551 de 04 de agosto de 2000. Institui o registro de bens culturais de natureza imaterial que constituem o patrimônio cultural brasileiro, cria o programa nacional do patrimônio e dá outras providências. Diário Oficial da República Federativa do Brasil, agosto de 2000.

Brulon, B. (2020). Descolonizar o pensamento museológico: reintegrando a matéria para re-pensar os museus. Anais Do Museu Paulista: História E Cultura Material, 28, 1-30. https://doi.org/10.1590/198202672020v28e1

Chuva, M. (2017). Possíveis narrativas sobre duas décadas de patrimônio: de 1982 a 2002. Revista do Patrimônio, 35(1), 79-104, Brasília-DF.
Chuva, M. R. R. (2009). Os arquitetos da memória: sociogênese das práticas de preservação do patrimônio cultural no Brasil (anos 1930-1940). Rio de Janeiro: Editora UFRJ.

Cunha, M. N. B. da. (2006). Teatro de memórias, palco de esquecimentos: Culturas Africanas e das diásporas negras em exposições. Tese apresentada ao Programa de Estudos Pós-Graduados em História da Pontifícia Universidade Católica de São Paulo - (PUC).

Cury, M. X. (2019). Museologia, comunicação e mediações culturais: curadoria, públicos e participações ativas e efetivas. MUSEOLOGIA e suas interfaces críticas [recurso eletrônico]: museu, sociedade e os patrimônios / [organizadores] Bruno Melo de Araújo. [et al]. - Recife: Ed. UFPE, 08-22. Disponível em: https:// orbi.uliege.be/bitstream/2268/239341/3/2019\%20 E-BOOK\%20REDE\%20MUSEOLOGIA.pdf Acesso em: 28/05/2020.

Fernández, L. A., Fernández, I. G. (2017). Diseño de exposiciones: concepto, instalación y montaje. Madrid: Alianza Editorial.

Ferrez, H. D., Bianchini, M. H. S. (1987). Thesaurus para acervos museológicos. Rio de Janeiro: Fundação Nacional Pró-Memória.

Flórez Crespo, M. del M. (2006). La museología crítica y los estudios de público en los museos de arte contemporáneo. Caso del museo de arte contemporáneo de Castilla y León, Musac. De Arte, 5, 231-243, Disponível em: <http:// nuevamuseologia.net/wp-content/uploads/2015/12/ Museologiacritica.pdf> Acesso em: 31/05/2020.

Freitas, A. G. B. de, Vilas-Boas, E. F., Nascimento, J. C. do. (2002). Pernambuco, Sergipe, São Paulo: Os caminhos do Colégio Inglês na educação feminina. Horizonte, Bragança Paulista, 20, 1-8, jan./dez. Disponível em: https://ri.ufs.br/bitstream/riufs/1063/1/ PernambucoSergipeS\%C3\%A3oPaulo.pdf. Acesso em 31 de maio de 2020.

Gomes, R., Santos, D., \& Ribeiro, C. (2015). Cores, cantos e ritos da cultura popular: um olhar fenomenológico sobre o encontro cultural de Laranjeiras, SE. Geosaberes, 6(1), 341 - 352. Retrieved from http://www.geosaberes.ufc. br/geosaberes/article/view/390

Gordillo Sánchez, Daniel Guillermo. (2017). Decolonización, bibliotecas y América Latina: notas para la reflexión. Investigación bibliotecológica, 31(73), 131-155. -https:// doi.org/10.22201/iibi.24488321xe.2017.73.57850

Guran, M. (2017). Sobre o longo percurso da matriz africana, pelo seu reconhecimento patrimonial como uma condição para a plena cidadania. Revista do Patrimônio, 
35(1), 213-226, Brasília-DF.

Jeria, V., Stáffora, V., Cohen, S., \& Pegoraro, A. (2020). Silêncio desafiador: reflexões entre museologia e antropologia. Revista Del Museo De Antropología, 13(3), 139-154. https://doi.org/10.31048/1852.4826. v13.n3.28892

Lamborghini, E. (2019). Antropologia de museus e representações de ascendência africana: perspectivas teóricas, debates e propostas. Revista Del Museo De Antropología, 12(3), 61-72. https://doi. org/10.31048/1852.4826.v12.n3.21990

Lima, A. R. (2012). Patrimônio cultural afrobrasileiro: as narrativas produzidas pelo Iphan a partir da ação patrimonial. (Dissertação de Mestrado). Curso de Mestrado Profissional em Preservação do Patrimônio Cultural. Iphan.

Lody, R. (2005). O Negro no museu brasileiro: construindo identidades. Rio de Janeiro: Bertrand Brasil.

Mott, L. R. B. (2008). Sergipe Colonial e Imperial: religião, família, escravidão e sociedade - 1591-1882. São Cristóvão: Editora UFS; Aracaju: Fundação Oviêdo Teixeira.

Nascimento, E. F. Villas-Boas C. (2004). do. A escola americana: origens da educação protestante em Sergipe (1886-1913). São Cristóvão: Grupo de Estudos e Pesquisa em História da educação/NPGED.
Oliveira, I. F. de. (2015). Por não querer servir ao seu senhor: os quilombos volantes do Vale do Cotinguiba (Sergipe Del Rey, século XIX) / Igor Fonséca de Oliveira. - Recife: O autor.

Reis, R. V. C. (2016). Sob a lupa de Mnemosine: apontamentos para identificação e mapeamento dos museus de Sergipe. TCC (Graduação em Museologia). Laranjeiras: UFS.

Resende, J. M. dos S. (2003). Entre campos e veredas da Cotinguiba: o espaço agrário em Laranjeiras (1850-1888). Dissertação (Mestrado em Geografia) - Programa de PósGraduação em Geografia. São Cristóvão: UFS.

Santana, L. B. (2011). Em busca de Zizinha: vestígios para a musealização da memória sobre Eufrozina Amélia Guimarães. TCC(Graduação em Museologia). Laranjeiras: UFS.

Santos, J. A. M. dos. (2019). A luta do povo quilombola, Mussuca: organização política e resistência em Sergipe. Dissertação (Mestrado em Geografia) UFS.

Silva, H. F. da., Reis, A. B. (2017). Ensino de História e Cultura Afro-brasileira: trabalhando personagens negros no pós-abolição. Disponível: http://www. ensinodehistoria2017.bahia.anpuh.org/resources/ anais/8/1506760382_ARQUIVO_HiagoeAdrianoEnsinodeHistoriaeCulturaAfro.pdf

Telles, M. P. O. (2013). Sergipenses: (escriptos diversos)/ M.P. Oliveira Telles. 2 ed. São Cristóvão: Editora UFS; Aracaju IHGSE. 